\title{
Correction: Census Tract Patterns and Contextual Social Determinants of Health Associated With COVID-19 in a Hispanic Population From South Texas: A Spatiotemporal Perspective
}

Cici Bauer ${ }^{1}$, PhD; Kehe Zhang ${ }^{1}$, MS; Miryoung Lee ${ }^{2}$, PhD; Susan Fisher-Hoch ${ }^{2}$, MD; Esmeralda Guajardo ${ }^{3}$, MA; Joseph McCormick², MD; Isela de la Cerda ${ }^{2}$, MS; Maria E Fernandez ${ }^{4}, \mathrm{PhD}$; Belinda Reininger ${ }^{5}$, DrPH

\footnotetext{
${ }^{1}$ Department of Biostatistics and Data Science, School of Public Health, The University of Texas Health Science Center at Houston, Houston, TX, United States

${ }^{2}$ Department of Epidemiology, Human Genetics and Environmental Science, School of Public Health, The University of Texas Health Science Center at Houston, Brownsville, TX, United States

${ }^{3}$ Cameron County Public Health, San Benito, TX, United States

${ }^{4}$ Department of Health Promotion and Behavior Sciences, School of Public Health, The University of Texas Health Science Center at Houston, Houston, TX, United States

${ }^{5}$ Department of Health Promotion and Behavior Sciences, School of Public Health, The University of Texas Health Science Center at Houston, Brownsville, TX, United States
}

\section{Corresponding Author:}

Cici Bauer, PhD

Department of Biostatistics and Data Science

School of Public Health

The University of Texas Health Science Center at Houston

1200 Pressler Street

Houston, TX, 77030

United States

Phone: 17135009581

Email: cici.x.bauer@uth.tmc.edu

\section{Related Article:}

Correction of: https://publichealth.jmir.org/2021/8/e29205

(JMIR Public Health Surveill 2021;7(8):e32870) doi: 10.2196/32870

In "Census Tract Patterns and Contextual Social Determinants of Health Associated With COVID-19 in a Hispanic Population From South Texas: A Spatiotemporal Perspective" (JMIR Public Health Surveill 2021;7(8):e29205), one error was noted.

Due to a system error, the name of one author, Joseph McCormick, was replaced with the name of another author on the paper, Isela de la Cerda. In the originally published paper, the order of authors was listed as follows:

Cici Bauer, Kehe Zhang, Miryoung Lee, Susan Fisher-Hoch, Esmeralda Guajardo, Isela de la Cerda, Isela de la Cerda, Maria E Fernandez, Belinda Reininger

This has been corrected to:

Cici Bauer, Kehe Zhang, Miryoung Lee, Susan Fisher-Hoch, Esmeralda Guajardo, Joseph

\section{McCormick, Isela de la Cerda, Maria E Fernandez, Belinda Reininger}

In the originally published paper, the ORCID of author Isela de la Cerda was incorrectly published as follows:

$$
\text { 0000-0002-5844-8102 }
$$

This has been corrected to:

$$
\text { 0000-0003-3625-8954 }
$$

The correction will appear in the online version of the paper on the JMIR Publications website on August 18, 2021, together with the publication of this correction notice. Because this was made after submission to PubMed, PubMed Central, and other full-text repositories, the corrected article has also been resubmitted to those repositories. 
This is a non-peer-reviewed article. Submitted 12.08.21; accepted 12.08.21; published 18.08.21.

Please cite as:

Bauer C, Zhang K, Lee M, Fisher-Hoch S, Guajardo E, McCormick J, de la Cerda I, Fernandez ME, Reininger B

Correction: Census Tract Patterns and Contextual Social Determinants of Health Associated With COVID-19 in a Hispanic Population

From South Texas: A Spatiotemporal Perspective

JMIR Public Health Surveill 2021;7(8):e32870

URL: https://publichealth.jmir.org/2021/8/e32870

doi: $\underline{10.2196 / 32870}$

PMID:

(C) Cici Bauer, Kehe Zhang, Miryoung Lee, Susan Fisher-Hoch, Esmeralda Guajardo, Joseph McCormick, Isela de la Cerda, Maria E Fernandez, Belinda Reininger. Originally published in JMIR Public Health and Surveillance (https://publichealth.jmir.org), 18.08.2021. This is an open-access article distributed under the terms of the Creative Commons Attribution License (https://creativecommons.org/licenses/by/4.0/), which permits unrestricted use, distribution, and reproduction in any medium, provided the original work, first published in JMIR Public Health and Surveillance, is properly cited. The complete bibliographic information, a link to the original publication on https://publichealth.jmir.org, as well as this copyright and license information must be included. 